\title{
The Geomechanical Height/Radius Ratio Applied to Analysis and Preser- vation of Neolithic Tumuli, with Examples from Álava (Spain)
}

\author{
L. M. Martínez-Torres*
}

Departamento de Geodinámica, University of the Basque Country, Spain

\begin{abstract}
The height/radius ratio of a tumulus and the angle of repose for the materials used in its construction permits one to: predict possible construction methods, calculate the path of geometric evolution before and after the current form and compare degrees of preservation. By way of example a Neolithic tumulus is compared with a modern-day one, both made out of identical lithology. Finally, comments are made on $\mathrm{h} / \mathrm{r}$ values for tumuli and tumuli with dolmens for the archaeological catalogue of Álava, in the Western Pyrenees.
\end{abstract}

Keywords: Stability; Construction; Preservation; Tumulus; Dolmen; Neolithic; Western Pyrenees.

\section{INTRODUCTION}

Tumuli are mounds or small hills constructed by piling fragments of stone on top of one or more burial places. On the inside of the tumulus there may be a dolmen or chamber made of stone slabs. A tumulus with an inner dolmen is called a dolmenic tumulus or, simply, dolmen. In Álava, in the Western Pyrenees (Fig. 1), the majority of catalogued tumuli and dolmens are from the Neolithic and Calcolithic ages [1]. In general, the geometry of the tumuli in question can be thought of as a regular circular based cone. In its description the height and the diameter of the base can be quantified, allowing simple morphological statistics to be produced [2] and [3]. Some of the excavated tumuli display basic internal structures, such as flagging or overlapping [4]. In no instance was the binding material or mortar conserved between the fragments of rock.

Due to the absence of mortar between the fragments of rock, the analysis of the tumuli has to be based on soil mechanics. In Geological Engineering one of the physical characteristics for soil is the internal angle of friction. This angle, which is also known as the angle of repose, corresponds to the limit at which the soil forms a stable slope.

In this article, a relationship is established for the angle of repose of a tumulus, represented by the height/radius ratio, and the angle of stability for the materials used in its construction. By way of example, a Neolithic tumulus is compared against a modern-day one, with observations made on the height/radius values for the tumuli and dolmens of Álava [1].

\section{METHODOLOGY}

If we consider tumuli to be regular circular based cones, this geometrical shape can be described by its height and radius. We can imagine that the construction materials for the tumulus have been heaped directly to produce a regular conical form. The height of the cone $h$, the radius of the cir-

*Address Correspondence to this Author at the Departamento de Geodinámica, University of the Basque Country, Spain; Tel: +34946012557; Fax: +34-946013500: E-mail: luismiguel.martinez@ehu.es

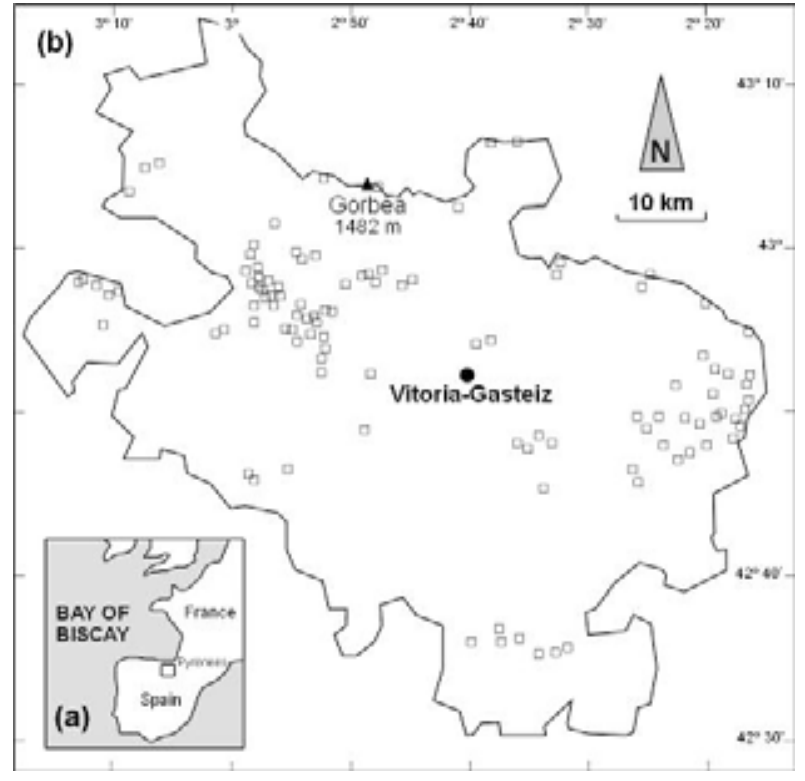

Fig. (1). (a) Location of Álava in the Western Pyrenees. (b) Distribution of tumuli and dolmenic tumuli in Álava. Modified from [1].

cle $r$ and the angle of the slope $\alpha$ are related using the following formula

$$
\operatorname{tag} \alpha=h / r
$$

The internal angle of friction $\alpha$ for the heaped materials will depend on the particle size, uniformity of the granulometry, the angularity of the particles, the clay content, compactness, density and, above all, the lithology. For any material, angle $\alpha$ can be calculated from standard laboratory tests, or from indirect evaluations whenever it is not possible to collect representative samples [5].

The tumuli in question contain a lot of sandstone and limestone fragments, with a certain amount of clay. If we refer to the Unified Soil Classification System, the construction materials used in the tumuli being studied correspond to GW-GC gravels [6]. This granulometry of well graded gravel with clay prevents representative samples from being 
studied and, in any case, an in situ geotechnical test would involve the partial destruction of the monuments.

In order to quantify the characteristics of gravel, Geological Engineering often uses pre-established values and ranges [7-10]. In our case, for the gravel composed of fragments of sandstone, the friction angle $\alpha$ can be taken as $35^{\circ}$ and for limestone gravel $30^{\circ}$. These values are for reference purposes only, given that each material should have undergone specific analysis, which was not done in this study.

\section{h/r Diagram}

Independently of the type of lithology, it is possible to relate the height, radius and internal angle of friction for each tumulus in a simple diagram (Fig. 2), based on formula (1), producing interesting interpretations.

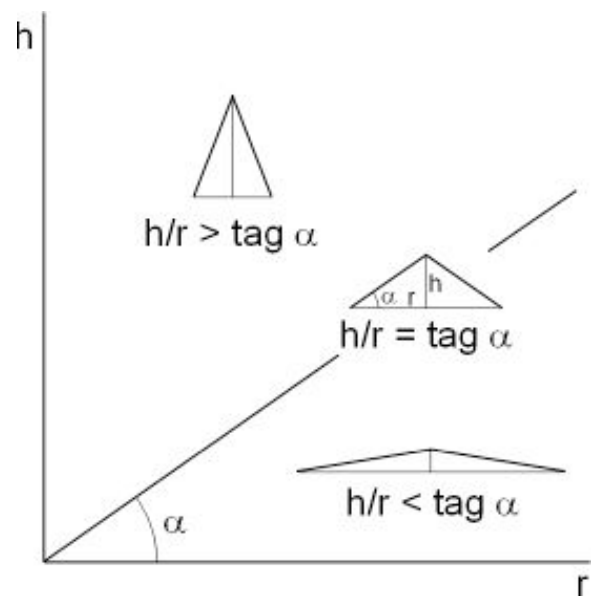

Fig. (2). h/r diagram contrasting height $h$ and radius $r$ for a tumulus. The $h / r=\operatorname{tag} \alpha$ line corresponds to the $\alpha$ angle of repose for the construction materials. Any tumuli located above this line must possess an internal structure or opus.

If the tumulus is constructed through direct heaping of material then it complies with formula (1). This implies that the tumulus is in equilibrium and that the slope angle $\alpha$ is stable. This state is shown in Fig. 2 by the line with slope $\alpha$.

Gravity and external factors, such as vibration or external loads, tend to diminish angle $\alpha$. This translates into an increased $r$ value and a decreased $h$ value, with a resulting flattening of the structure. This state is represented in Fig. 2 by the bottom triangle, where $h / r<\operatorname{tag} \alpha$. Any tumulus falling into this category was either originally built with these proportions or has evolved from a former structure with greater $\mathrm{h} / \mathrm{r}$ values.

The top triangle in Fig. 2 represents $h / r>\operatorname{tag} \alpha$. The tumuli that fall into this category have slopes greater than the angle of stability. This implies a more or less organised construction method, that exceeds the natural angle of equilibrium for this class of material. That is to say, tumuli in which $h / r>\operatorname{tag} \alpha$ possess an internal opus.

\section{Path of Geometric Evolution}

By assuming the volume of the tumulus remains constant and that it conserves its regular conical shape, it is possible to work out the geometric evolution of the tumulus. In a regular cone the volume can be calculated from the formula:

or

$$
V=1 / 2 \cdot \pi \cdot r^{2} \cdot h
$$

$$
2 V / \pi \cdot h=r^{2}
$$

For a constant volume formula (3) is an exponential function and can be represented graphically in a $h / r$ diagram (Fig. 3).

Any tumulus can be represented in Fig. 3 with the topmost tip at $T p$. A progressive flattening of a structure will displace this point in a downward direction, always within the constant volume curve. In this way, if flattening occurs then the theoretical tumulus represented by point $T p$ may be represented in the future by, for example, point $T a$ in Fig. 3.

If it is known that there is some kind of structure on the inside of the tumulus then it is quite probable that the original tumulus will be situated above the $h / r=\operatorname{tag} \alpha$ line on the constant volume curve. In our case, the present-day tumulus represented by $T p$, which does have an internal opus, would have been originally located somewhere above the curve, e.g. at point $T b$ in Fig. 3.

Therefore, the exponential curve represented in the $h / r$ diagram for Fig. 3 shows the possible route or path of geometric evolution over time for a tumulus with a constant volume.

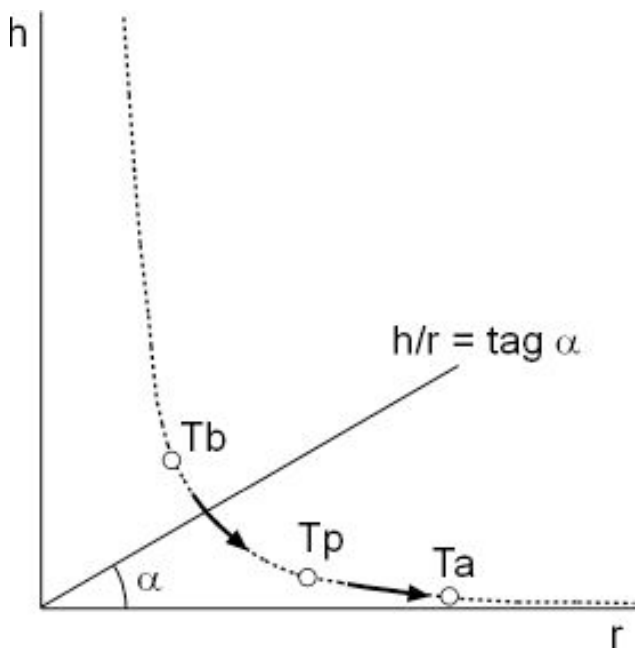

Fig. (3). $h / r$ diagram with an exponential curve for constant volume, the $\alpha$ angle of repose for the materials employed and the evolutive path for a theoretical tumulus. If, in the future, the current tumulus represented at point $T p$ continues to flatten with a constant volume, it can be projected to, for example, point $T a$. If, in addition, the current tumulus $T p$ possesses an internal structure, its original projection will be located on the curve above $T p$, for example at point $T b$.

\section{Degree of Preservation}

The path shown in Fig. 3 indicates the degree of geometric evolution for a tumulus, or in other words, the degree of preservation. Within the exponential curve for constant volume, higher $h / r$ values imply a greater degree of preservation. 
Nevertheless, the $h / r$ ratio is non dimensional value independent of volume, only related to lithological characteristics. Therefore, for identical lithologies, the degree of evolution or preservation is represented by the $h / r$ value, regardless of the volume of the structure. The smaller this value is, the lower the degree of preservation and, vice versa, the greater the $h / r$ value, the higher the degree of preservation.

In short, for identical lithologies, in comparative analysis of tumuli, the $h / r$ ratio can be used as indicators of preservation or evolution.

\section{EXAMPLES}

\section{The Gorbea Tumulus}

A tumulus was recently discovered on the mountain of Gorbea, the highest point in Álava (Fig. 1). Due to its type and shape, the man-made structure can be attributed to the Neolithic period (Fig. 4). Because it is close to the highest point in this region it is a frequently visited area. It is traditional among mountaineers to build small mounds as guide markers. Hardly $200 \mathrm{~m}$ away from the Neolithic tumulus there is a modern-day tumulus, or mound, with metric dimensions (Fig. 5).

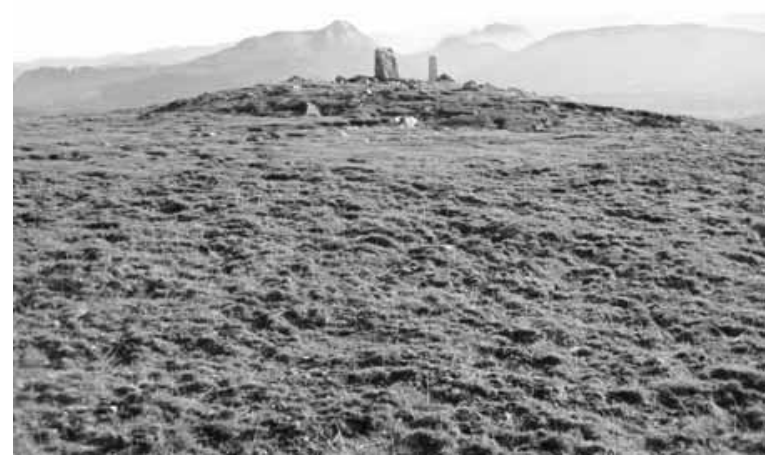

Fig. (4). Neolithic tumulus at Gorbea constructed with fragments of Albian sandstone. Its dimensions are $1.2 \mathrm{~m}$ high, $4.5 \mathrm{~m}$ radius and a slope of $15^{\circ}$. Two official boundary markers can be seen on the top section.

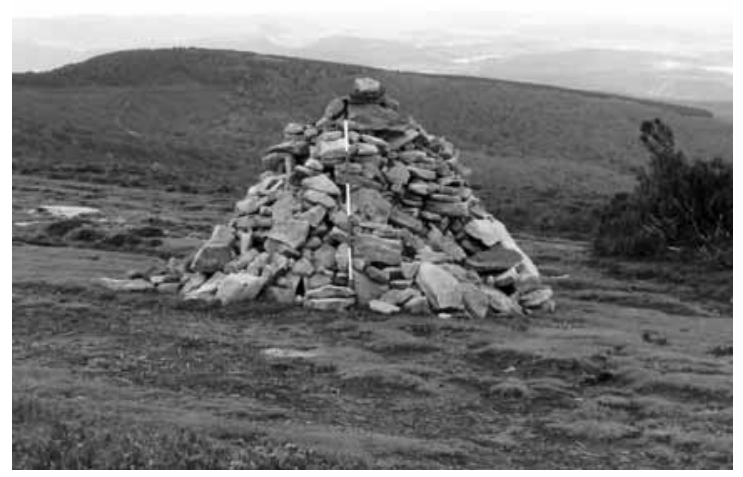

Fig. (5). Modern-day tumulus made from fragments of Albian sandstone, located some $200 \mathrm{~m}$ away from the Gorbea tumulus (Fig. 4). Its dimensions are $1.4 \mathrm{~m}$ high, $1.15 \mathrm{~m}$ radius and a slope of $43^{\circ}$.
The lithology and size of the fragments in both tumuli are identical. By applying the theory of actualism, it would seem clear that the geomechanical behaviour of both structures is also identical. This similarity has made it possible to compare both structures (Fig. 6).

The construction material used is Albian sandstone gravel. In the Neolithic tumulus sand and clay are also visibly present. In any case, from a Geological Engineering perspective, the angle of repose for the slope on both structures can be taken at a value of $35^{\circ}$.

The dimensions of the Neolithic tumulus are $1.2 \mathrm{~m}$ high and $4.5 \mathrm{~m}$ radius, which gives a ratio of:

$$
h / r=1.2 / 4.5=0.26
$$

This value is equivalent to a slope of $15^{\circ}$. If we apply formula (2) a volume $38.17 \mathrm{~m}^{3}$ is obtained. In the modern-day tumulus the relation is $1.4 / 1.15$, which represents a slope of $43^{\circ}$ and a volume of $2.9 \mathrm{~m}^{3}$.

The $h / r$ diagram in Fig. (6) shows the current position for the Neolithic tumulus $T p$ and the modern-day tumulus $C p$, the steepness of their respective slopes and the constant volume curves for both structures. The diagram also includes a $35^{\circ}$ reference line, the angle at which these sandstone based gravels form a natural slope in equilibrium. In Fig. 6, the modern-day tumulus $C p$ is above the line of repose, which suggests an internal structure. Mountaineers who place fragments of rock on the tumulus, generally on the highest section, are likely to ensure that the structure remains in equilibrium. In this case the final result, although there is no predetermined opus, is an ordinary dry stone construction resulting from random piling of sandstone fragments (Fig. $5)$.

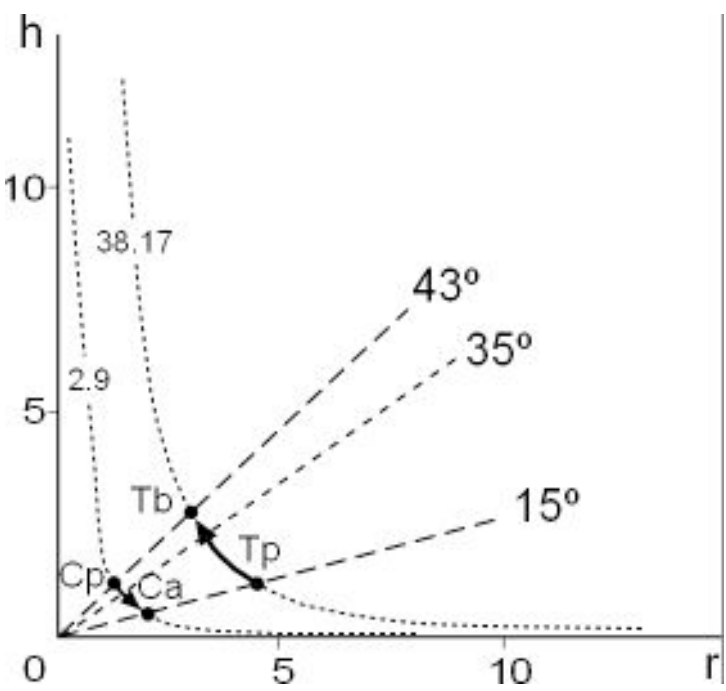

Fig. (6). h/r diagram with constant volume curves for the Neolithic Gorbea tumulus (Fig. 4) represented by point Tp and the neighbouring modern-day tumulus (Fig. 5) represented by $\mathrm{Cp}$. The arrows indicate the possible path of geometric evolution. Point Te represents the Neolithic tumulus with a slope in equilibrium and point $\mathrm{Tb}$ it possible original geometry. Point $\mathrm{Ca}$ represents the possible future geometry of the modern-day tumulus. 
In the future it is likely that, over a period of time equal to the current age of the Neolithic tumulus, the cairn $C p$ will evolve to point $C a$, with a slope of $15^{\circ}$. By applying formulas (1) and (2), for a constant volume of $2.9 \mathrm{~m}^{3}$, it can be deduced that $\mathrm{Ca}$ will then have a height of $0.5 \mathrm{~m}$ and a radius of $1.91 \mathrm{~m}$.

With regard to the Neolithic tumulus, by applying reverse logic and assuming that it was constructed using stones similar to those used in the modern-day mound, Fig. 6 shows the path rising between $T p$ and $T b$. Where point $T b$ corresponds to a cone $2.76 \mathrm{~m}$ high with a radius of $2.97 \mathrm{~m}$.

If it is not known whether there are internal structures, the maximum position for the original state of the Neolithic tumulus would be placed at point $T e$, where the constant volume curve intersects the stability angle line for $35^{\circ}$ (Fig. 6). In this case, tumulus $T e$ has a height of $2.28 \mathrm{~m}$ and a radius of $3.26 \mathrm{~m}$. In any case, verifying the absence of internal structures, the original Neolithic tumulus would be placed on the curve for $38.17 \mathrm{~m}^{3}$, between points $T p$ and $T e$.

\section{Tumuli and Dolmens of Álava}

Table I, Table II and Fig. 7 have been produced using the dimensions of tumuli and tumuli with dolmens from the archaeological catalogue of Álava [1]. All of the monuments in question are located within the field below the lines of equilibrium for $30^{\circ}$ in the case of limestone gravels and $35^{\circ}$ for sandstone gravels. Only the dolmen at Layaza, reference number 7009 in Table II, exceeds this angle. Due to the fact that this has been excavated, its degree of preservation is not outstanding [11] which makes it difficult to establish its original dimensions. In addition to which, a study of the inner chamber suggests that its internal structure does not correspond to megalithic building methods employed in the area, so it may well have been remodelled [12].

Discarding this particular dolmen, all the other monuments display a certain degree of evolution below the angle of equilibrium. The degree of evolution, or the opposite, the degree of preservation, are given in Table I and Table II by the $\mathrm{h} / \mathrm{r}$ value, which is equal to the tag $\alpha$ value or directly by the angle $\alpha$ of the slope. The tables have been arranged from lowest to highest degree of preservation. Obviously, the geometrical elements studied and their degree of evolution are directly linked with their chronology: those tumuli in a better state of preservation could be the most modern and vice versa. Nevertheless, the considered archaeological catalogue [1] does not have sufficient absolute dating to be able to compare the age of the monument with its degree of preservation.

If we check the lithology, we can see that those dolmen constructed with limestone have an average slope of $9.6^{\circ}$ (Table II), which is similar to the $9.1^{\circ}$ for the tumuli that were constructed mainly from limestone gravels (Table I). However, the average slope for the dolmenic tumuli constructed with sandstone gravels is $19.8^{\circ}$ (Table II). This observation ties in with the angle of stability values already mentioned, which are greater for sandstones $\left(35^{\circ}\right)$ than for limestones $\left(30^{\circ}\right)$. Meaning that any comparative analysis of tumuli should make allowances for the lithology.

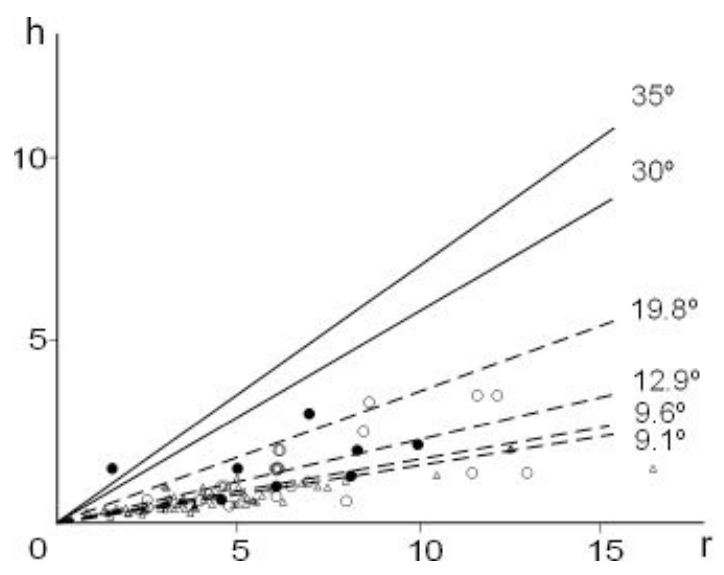

Fig. (7). Projection on a $\mathrm{h} / \mathrm{r}$ diagram for the tumuli (Table I) and dolmens (Table II) of the archaeological catalogue of Álava [1]. The values on the right indicate the different steepnesses of slopes mentioned in the text. The triangles correspond to tumuli and the circles to dolmenic tumuli. Tumuli and dolmens constructed with limestone gravels are shown in white and sandstone gravels in black.

Table I. Tumuli for the archaeological catalogue of Álava [1] arranged according to $\mathrm{h} / \mathrm{r}$ ratio. Dimensions in metres. The symbols associated with the reference numbers correspond to the lithology of the gravels employed in their construction. (*): Upper cretaceous sandstones; $(* *)$ : lower cretaceous limestones; underlined: Tertiary limestones; normal text: Upper Cretaceous limestones.

\begin{tabular}{|c|c|c|c|c|}
\hline Reference & h & $\mathbf{r}$ & $\mathbf{h} / \mathbf{r}$ & $\alpha$ \\
\hline 5011 & 0.3 & 3.7 & 0.08 & $4.6^{\circ}$ \\
\hline 5009 & 1.5 & 16.5 & 0.09 & $5.1^{\circ}$ \\
\hline$\underline{5035}$ & 0.6 & 6.25 & 0.09 & $5.1^{\circ}$ \\
\hline$\underline{2009}$ & 0.5 & 5 & 0.1 & $5.7^{\circ}$ \\
\hline 4014 & 0.6 & 5.5 & 0.1 & $5.7^{\circ}$ \\
\hline 4017 & 0.25 & 2.35 & 0.1 & $5.7^{\circ}$ \\
\hline 4021 & 0.5 & 4.95 & 0.1 & $5.7^{\circ}$ \\
\hline$\underline{5036}$ & 0.4 & 3.85 & 0.1 & $5.7^{\circ}$ \\
\hline 4015 & 0.5 & 4.25 & 0.11 & $6.3^{\circ}$ \\
\hline 5016 & 0.4 & 3.5 & 0.11 & $6.3^{\circ}$ \\
\hline$\underline{5034}$ & 0.6 & 5.45 & 0.11 & $6.3^{\circ}$ \\
\hline 7003 & 1.25 & 10.45 & 0.11 & $6.3^{\circ}$ \\
\hline 3009 & 0.4 & 3.25 & 0.12 & $6.8^{\circ}$ \\
\hline 5023 & 0.45 & 3.75 & 0.12 & $6.8^{\circ}$ \\
\hline 3015 & 0.7 & 5.1 & 0.13 & $7.4^{\circ}$ \\
\hline 4003 & 1 & 7.25 & 0.13 & $7.4^{\circ}$ \\
\hline 4005 & 0.75 & 5.7 & 0.13 & $7.4^{\circ}$ \\
\hline 4013 & 0.4 & 2.9 & 0.13 & $7.4^{\circ}$ \\
\hline 4016 & 0.7 & 5.25 & 0.13 & $7.4^{\circ}$ \\
\hline 4019 & 0.2 & 1.5 & 0.13 & $7.4^{\circ}$ \\
\hline
\end{tabular}


Table I. Con....

\begin{tabular}{|c|c|c|c|c|}
\hline Reference & h & $\mathbf{r}$ & $\mathbf{h} / \mathbf{r}$ & $\alpha$ \\
\hline 5004 & 0.7 & 5.25 & 0.13 & $7.4^{\circ}$ \\
\hline 5017 & 0.4 & 3 & 0.13 & $7.4^{\circ}$ \\
\hline 5022 & 1 & 7.5 & 0.13 & $7.4^{\circ}$ \\
\hline 4002 & 1.15 & 8 & 0.14 & $8^{\circ}$ \\
\hline 4010 & 0.35 & 2.45 & 0.14 & $8^{\circ}$ \\
\hline 4011 & 0.3 & 2 & 0.15 & $8.5^{\circ}$ \\
\hline 4012 & 0.3 & 2 & 0.15 & $8.5^{\circ}$ \\
\hline 4018 & 0.65 & 4.1 & 0.15 & $8.5^{\circ}$ \\
\hline 5025 & 0.35 & 2.25 & 0.15 & $8.5^{\circ}$ \\
\hline$\underline{5033}$ & 0.9 & 5.95 & 0.15 & $8.5^{\circ}$ \\
\hline 7018 & 0.5 & 3.3 & 0.15 & $8.5^{\circ}$ \\
\hline 3005 & 2 & 12.5 & 0.16 & $9.1^{\circ}$ \\
\hline 3006 & 2 & 12.5 & 0.16 & $9.1^{\circ}$ \\
\hline 3008 & 1.1 & 6.75 & 0.16 & $9.1^{\circ}$ \\
\hline 3047 & 0.4 & 2.5 & 0.16 & $9.1^{\circ}$ \\
\hline 5001 & 0.5 & 3 & 0.16 & $9.1^{\circ}$ \\
\hline 5020 & 0.5 & 3 & 0.16 & $9.1^{\circ}$ \\
\hline 3010 & 0.7 & 4.1 & 0.17 & $9.6^{\circ}$ \\
\hline $3119(*)$ & 0.6 & 3.5 & 0.17 & $9.6^{\circ}$ \\
\hline 5018 & 0,6 & 3.45 & 0.17 & $9.6^{\circ}$ \\
\hline 3013 & 0.65 & 3.5 & 0.18 & $10.2^{\circ}$ \\
\hline 5010 & 0.8 & 4.3 & 0.18 & $10.2^{\circ}$ \\
\hline 3124 & 1 & 5 & 0.2 & $11.3^{\circ}$ \\
\hline $330(* *)$ & 0.7 & 3.25 & 0.21 & $11.9^{\circ}$ \\
\hline 2001 & 0.85 & 4 & 0.21 & $11.9^{\circ}$ \\
\hline 4007 & 1 & 4.7 & 0.21 & $11.9^{\circ}$ \\
\hline 5015 & 0.4 & 1.9 & 0.21 & $11.9^{\circ}$ \\
\hline 5024 & 0.65 & 3 & 0.21 & $11.9^{\circ}$ \\
\hline 5026 & 0.3 & 1.4 & 0.21 & $11.9^{\circ}$ \\
\hline 3014 & 0.7 & 3.1 & 0.22 & $12.4^{\circ}$ \\
\hline 4008 & 0.3 & 1.3 & 0.23 & $12.9^{\circ}$ \\
\hline 4006 & 0.3 & 1.25 & 0.24 & $13.5^{\circ}$ \\
\hline 4020 & 1.2 & 5 & 0.24 & $13.5^{\circ}$ \\
\hline 5003 & 0.4 & 1.65 & 0.24 & $13.5^{\circ}$ \\
\hline 5002 & 1 & 4 & 0.25 & $14^{\circ}$ \\
\hline$\underline{2011}$ & 0.95 & 3 & 0.31 & $17.2^{\circ}$ \\
\hline 3004 & 1 & 3 & 0.33 & $18.3^{\circ}$ \\
\hline 4009 & 0.3 & 0.85 & 0.35 & $19.3^{\circ}$ \\
\hline Average & 0.68 & 4.44 & 0.16 & $9.1^{\circ}$ \\
\hline
\end{tabular}

Table II. Tumuli with dolmen from the archaeological catalogue of [1] arranged according to $h / r$ ratio. Dimensions in metres. Symbol system identical to Table I.

\begin{tabular}{|c|c|c|c|c|}
\hline Reference & $h$ & $r$ & $h / r$ & $\alpha$ \\
\hline 7016 & 0.6 & 8.1 & 0.07 & $4^{\circ}$ \\
\hline 7010 & 3 & 32 & 0.09 & $5.1^{\circ}$ \\
\hline 5007 & 1.4 & 13 & 0.1 & $5.7^{\circ}$ \\
\hline 5012 & 0.5 & 4.7 & 0.1 & $5.7^{\circ}$ \\
\hline$\underline{3058}$ & 0.75 & 6 & 0.11 & $6.3^{\circ}$ \\
\hline 5008 & 1.4 & 11.5 & 0.12 & $6.8^{\circ}$ \\
\hline 5021 & 0.6 & 4.5 & 0.13 & $7.4^{\circ}$ \\
\hline$\underline{3068}$ & 1 & 6.5 & 0.15 & $8.5^{\circ}$ \\
\hline 5014 & 0.6 & 4 & 0.15 & $8.5^{\circ}$ \\
\hline 7008 & 1.3 & 8.2 & 0.15 & $8.5^{\circ}$ \\
\hline 7011 & 1.1 & 7 & 0.15 & $8.5^{\circ}$ \\
\hline$\underline{2010}$ & 1.5 & 6 & 0.16 & $9.1^{\circ}$ \\
\hline$\underline{3051}$ & 1.5 & 6 & 0.16 & $9.1^{\circ}$ \\
\hline$\underline{3054}$ & 0.4 & 2.5 & 0.16 & $9.1^{\circ}$ \\
\hline$\underline{3067}$ & 1 & 6 & 0.16 & $9.1^{\circ}$ \\
\hline 7017 (**) & 2.15 & 10 & 0.21 & $11.9^{\circ}$ \\
\hline 5019 & 1 & 4.5 & 0.22 & $12.4^{\circ}$ \\
\hline $7004(*)$ & 1 & 4.5 & 0.22 & $12.4^{\circ}$ \\
\hline $7014(* *)$ & 2 & 8.4 & 0.23 & $12.9^{\circ}$ \\
\hline 5013 & 0.6 & 2.5 & 0.24 & $13.5^{\circ}$ \\
\hline 3123 & 1.5 & 6 & 0.25 & $14^{\circ}$ \\
\hline $7005(* *)$ & 1.5 & 6 & 0.25 & $14^{\circ}$ \\
\hline 7024 & 3.5 & 12.2 & 0.28 & $15.6^{\circ}$ \\
\hline $7001(* *)$ & 2.5 & 8.5 & 0.29 & $16.2^{\circ}$ \\
\hline 7011 & 3.5 & 11.7 & 0.29 & $16.2^{\circ}$ \\
\hline $361(*)$ & 1.5 & 5 & 0.3 & $16.7^{\circ}$ \\
\hline $7019(* *)$ & 2 & 6.2 & 0.32 & $17.7^{\circ}$ \\
\hline$\underline{3066}$ & 2 & 6 & 0.33 & $18.3^{\circ}$ \\
\hline 7015 & 3.3 & 8.7 & 0.37 & $20.3^{\circ}$ \\
\hline $366(*)$ & 3 & 7 & 0.42 & $22.8^{\circ}$ \\
\hline $7009{ }^{(* *)}$ & 1.5 & 1.5 & 1 & $45^{\circ}$ \\
\hline Average & 1.58 & 7.57 & 0.23 & $12.9^{\circ}$ \\
\hline $\begin{array}{l}\text { Average sand- } \\
\text { stones }\end{array}$ & 1.9 & 6.34 & 0.36 & 19.8 \\
\hline $\begin{array}{l}\text { Average lime- } \\
\text { stones }\end{array}$ & 1.45 & 8.07 & 0.17 & $9.6^{\circ}$ \\
\hline
\end{tabular}




\section{CONCLUSIONS}

The geomechanical behaviour of materials employed in the construction of tumuli can be linked with their height $h$ and radius $r$ dimensions. The $h / r$ ratio, or its equivalent $\alpha$ angle for the slope, allow the structure to be characterised in relation to the angle of repose for the materials used (Fig. 2). If the angle of the slope for the tumulus is greater than the angle of repose this would imply the presence of an internal structure or opus.

By accepting that the tumulus changes geometrically over time due to progressive flattening, reducing $h$ and increasing $r$ and taking the volume of construction material to be constant, it is possible to work out the path of geometric evolution for the tumulus, before and after its current geometry (Fig. 3).

For identical lithological characteristics, the adimensional $h / r$ value makes it possible to compare degrees of evolution or preservation for tumular structures. A higher $h / r$ values represents a lower degree of evolution, or in other words, a greater degree of preservation. If tumuli with different lithologies are compared then the internal angle of friction for each material should be taken into consideration.

The $h / r$ ratio and its graphical representation has been applied to the tumuli and dolmens for the archaeological catalogue of Álava [1]. In the same way, the Neolithic Gorbea tumulus (Fig. 4) has been compared with a modern-day tumulus (Fig. 5). In both cases it has been possible to apply quantifiable Geological Engineering criteria to the description and comparative analysis of tumular structures.

\section{REFERENCES}

[1] Instituto Alavés de Arqueología, Carta Arqueológica de Álava, Vitoria-Gasteiz: Diputación Foral de Álava, 1987.

[2] A. Ciprés , F. Galilea and L. López, "Dólmenes y túmulos de las sierras de Guibijo y Badaya. Planteamiento para su estudio a la vista de los últimos descubrimientos", Estudios de Arqueología Alavesa vol. 9, pp. 65-125, 1978.

[3] F. Galilea, "Prospecciones en la sierra de Bóveda. Hallazgo de algunos campos tubulares", Estudios de Arqueología Alavesa, vol. 9, pp. 127-140, 1978.

[4] F. Galilea, "Catálogo de túmulos y campos tumulares de Euskalerría. Su análisis", Kobie, vol. 10, pp. 421-447, 1980.

[5] F. J. Ayala and J. M. Rodríguez, Manual para el diseño y construcción de escombreras y presas de residuos mineros, Madrid: Instituto Geológico y Minero de España,1986.

[6] T. W. Lambe and R. V. Whitman, Soil mechanics, New York: John Wiley \& Sons, 1979

[7] L. I. González de Vallejo, M. Ferrer, L. Ortuño and C. Oteo, Ingeniería Geológica, Madrid: Pearson Educación, 2002.

[8] B. K. Hough, Basic Soils Engineering, New York: The Ronald Press Company, 1957.

[9] J. A. Jiménez and Justo J. L., Geotecnia y cimientos I. Propiedades de los suelos y de las rocas, Madrid: Editorial Rueda, 1975.

[10] P. H. Rahn, Engineering Geology. An environmental approach, Elsevier ed., 1986.

[11] J. M. Barandiarán and D. Fernández, "Excavaciones en Álava (1935-1947)", Boletín Institución Sancho el Sabio, vol. 2, pp. 5187, 1958.

[12] L. M. Martínez-Torres, "The technique of dolmen construction in the determination of a seism around the year 2,700 B.C.", Museo de Ciencias Naturales de Álava, vol. 12 pp. 25-31, 1997. 